\title{
advances
}

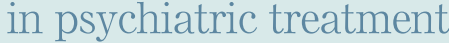

\section{CPD Online}

161 New from CPD Online

\section{Articles}

162 Rethinking placebo in psychiatry: the range of placebo effects Daniel McQueen, Sarah Cohen, Paul St John-Smith \& Hagen Rampes

171 Rethinking placebo in psychiatry: how and why placebo effects occur Daniel McQueen, Sarah Cohen, Paul St John-Smith \& Hagen Rampes

181 Post-traumatic stress disorder: new directions in pharmacotherapy Ben Green

191 Mindfulness-based interventions in secure settings: challenges and opportunities Dumindu Witharana \& Gwen Adshead

203 Using psychodynamic principles in formulation in everyday practice Alison Summers \& Brian Martindale

212 Recent developments in the management of delusional disorders Christopher F. Fear

221 Teamwork: the art of being a leader and a team player Josie Jenkinson, Clare Oakley \& Fiona Mason

229 Promoting children's resilience to parental mental illness: engaging the child's thinking

Alan Cooklin

240 Correction

Refreshment

201 Managing physical risk in anorexia nervosa

William Rhys Jones, John F. Morgan \& Jon Arcelus 